\title{
Fountain of Knowledge or Web of Deceit? A Look at Some Moroccan Stu- dents' Use of the Internet
}

\author{
Eirlys E. Davies* and Abdelâli Bentahila
}

Abdelmalek Essaâdi University, Tangier, Morocco

\begin{abstract}
The paper presents a preliminary investigation of some Moroccan students' use of the Internet, finding that they are more concerned with obtaining everyday information and communicating with their peers rather than exploring new horizons, and that they often fail to discriminate valid information from hoaxes. It is therefore argued that the impact of the Internet as a diffuser of knowledge and an enhancer of intercultural understanding cannot be taken for granted.
\end{abstract}

The Internet and the World Wide Web are constantly being hailed as one of the greatest revolutions in social history. We can distinguish two major reasons for this. Metaphors describing the web as an information superhighway, a fountain of knowledge, or a gateway to the world reflect some of the ways in which its possibilities have been perceived. One of the pervading images used to describe the impact of Internet use on the world is the notion of the democracy of information (Friedman, 1999) - the idea that the net has made accessible to the masses a wealth of information that formerly was available only to an elite. To quote Kofi Anan, as far back as 1998: 'The quantity and quality of available information is changing dramatically every day, in every country, in every corner of the world. Citizens are gaining greater access to information, too.' (UN Press Release, 1998). A second set of images are those which focus on the Internet as a meeting place, a means of crossing frontiers and bridging oceans, facilitating communication between individuals around the world and supposedly thereby enhancing intercultural understanding. A corollary of this second idea is the often expressed view that Internet communication can be exploited as an educational tool for promoting intercultural awareness and communication skills. For instance, many studies have recommended the use of emailing and participation in Internet forums as part of courses in language and communication (see, for instance, Chen 1998); these strong claims may well need to be tempered. The Internet does indeed give access to a seemingly unlimited amount of accurate, up-to-date and authoritative information. Unfortunately, it also offers an unrivalled collection of outdated, distorted and downright false information. Some of this is only unintentionally misleading (old web pages, personal websites and blogs which represent only their authors' views). But alongside this is the extensive use of the Internet to disseminate propaganda, disinformation and misinformation for purposes which may range from the merely ludic to the seriously malevolent. As Internet communication has expanded, Internet hoaxes have proliferated, to be followed, fortunately, by a host of sites like Snopes and Hoaxbusters, aimed at exposing them. There are also numer-

*Address correspondence to this author at the King Fahd School of Translation, Abdelmalek Essaadi University, BP 410, Tangier, Morocco;

E-mail: eirlys_davies@hotmail.com ous websites provided by educational institutions which offer guidelines on how to evaluate the information offered on the web. For of course, what the web offers is information, but not necessarily knowledge; the latter is attained only with experience and/or training in how to handle information.the web. For of course, what the web offers is information, but not necessarily knowledge; the latter is attained only with experience and/or training in how to handle information.

Claims about the role of the Internet in promoting intercultural communication also deserve closer scrutiny. First, the idea of the Internet as a place where members of different cultures interact freely and easily understand one another is not shared by all observers. After all, there is no real reason why we should expect messages mediated via a computer rather than some other means, such as face-to-face interaction, to enhance understanding between people of very different backgrounds.

Moreover, it has been argued that the online communication strategies adopted by different groups do not necessarily correspond to their cultural norms in other contexts (Hanna $\&$ de Nooy, 2004). Some have suggested that rather than being a site for cultural diversity, the Internet is displaying a tendency towards cultural uniformity, either because it is becoming a culture-free environment, or because users of different backgrounds are converging towards one dominant set of behavioral patterns - these patterns being close to American communication patterns, rather than those of any other culture, because of the origins of the Internet and the predominance of Americans among its users. Hargittai (1998) argues that this cultural domination has led to a perpetuation of the inequality between the developed and less developed nations.

Still another view is that Internet users remain enclosed in their own cultures, which may be relatively impermeable and inaccessible to outsiders. There have been a number of studies suggesting that different cultures maintain their own cognitive styles even on the Internet; for instance, Faiola and Matei (2005) report on differences between Chinese and American web design and claim that users get on better when using content produced by members of their own cultures. Similarly, Hongladorom (2007) reports on how Thai websites are preserving their own cultural values despite the pressures of globalization. 
Finally, it seems important to recognise that, while access to the Internet is available to individuals of different cultures, any interaction between them is obviously partly dependent on language; while the monolingual speaker of English has access to material of very diverse origins, the monolingual user of Japanese or Arabic has much less scope for exploring others' material. And even if Japanese and Arab internet users interact, this is likely to be via the medium of English, so that the encounter will be between Anglophone Japanese and Arabs, who may not be representative of most of their fellows. The utopian idea of the Internet as a place where boundaries are broken down may thus be far removed from the truth.

Moreover, just as the web is frequently a transmitter of false information, it is also used to promote prejudices and negative stereotypes of certain groups. Here again the situation can be assessed by looking at the sites that have sprung up to inform users of this material; for instance, the latest edition of the Hate Directory (Franklin, 2008) lists 157 pages of sites promoting hostility or violence against groups on the grounds of race, religion, ethnic group, gender or sexual orientation. Unfortunately, the naïve Internet user may not always recognise these sites for what they are, but may assume they contain objective information.

It is also important to recognize that the facility of Internet communication may of course serve, not to further links with outsiders, but to reinforce the bonds within a group linked by culture, outlook or background, which may then tend to close in on itself and strengthen the boundaries between itself and other groups. This can of course be an invaluable strategy for the maintenance of minority groups and the strengthening of local communities (see, for instance Beckett, 2004). But it can also reinforce divisions; thus Dahan (2003) reports with disappointment that the use of the Internet has emphasized divisions between Jews and Arabs in Israeli society, while failing to provide the Palestinian Israelis with any enhancement of their identity. Internet networks can of course also serve to strengthen extremist positions: an individual who is hostile to some other community may find it easy to encounter likeminded individuals via the Internet. In other words, the qualities of computer-mediatedcommunication which make it a valuable tool for disseminating knowledge and promoting dialogue are also the same qualities which lend it to use for propaganda and the promotion of divisions and prejudices.

Previous studies of Internet users have in many cases adopted uses and gratifications theory, as developed by Blumler and Katz (1974) and originally used for the investigation of motives for using other mass media, notably radio and television. Within this framework, media users are seen as active consumers who are aware of their needs and goaldirected, selecting the media which will best gratify these needs. While this theory has actually been criticized for assuming too great a degree of control on the part of television viewers (Severin \& Tankard, 1997), its assumptions seem particularly valid in the case of Internet users, who do indeed to a large extent choose which sites to visit, which pages to open, which links to pursue, and how and to what extent they interact with this material.

In early uses and gratifications studies, a number of researchers proposed quite similar categories of needs which could be gratified via the use of mass media. McQuail, Blumler and Brown (1972), for instance, list four types of gratification: diversion, personal relations, personal identity and surveillance, while Katz, Gurevitch and Haas (1973) identify five categories covering very much the same range of needs: cognitive needs, affective needs, personal integrative needs, social integrative needs, and tension release needs.

More recently, these or similar categories have been found useful in identifying Internet users' possible gratifications. Ferguson and Perse (2000) compared television and the Internet and identified entertainment, passing the time, relaxation and social information as factors motivating use of the Internet. Stafford (2004) notes the generally recognized distinction between content gratifications (as derived from the information obtained) and process gratifications (relating to the experience of using the Internet), and adds a third category, social gratifications, covering the use of the Internet for communication and transactions.

Previous studies of Internet users have tended to focus on populations in the industrialized world where the Internet is already well established and accessible to a large proportion of the population. Little attention seems to have been paid to the situation in developing countries, and in particular in Africa. This is understandable, since the impact of the Internet in such societies is still limited, though growing rapidly. Yet in some ways the role of the Internet in the third world may be particularly significant, as will be suggested below.

The present paper will therefore offer a preliminary exploration of the use of the Internet and the World Wide Web by one category of young people in Morocco. While Morocco is a developing country not particularly well-endowed with the latest information and communications technology, it is nevertheless one whose community of Internet-users is expanding rapidly. According to Internet World Stats, in December 2007 Morocco rated second among African countries in terms of absolute numbers of Internet users, behind Nigeria and ahead of Egypt (and very far ahead of its North African neighbours Algeria and Tunisia). On this date the number of Moroccan users was estimated at 6,100,000, representing $18.1 \%$ of the population. This figure compares with 4,600,000 in 2006, 1 million in 2005, and a mere 100,000 in 2000 , and the rate of growth between 2000 and 2007 is calculated at $6,000.0 \%$, one of the highest among African countries. However, the digital divide is clearly seen within Morocco, where the majority of the population is excluded from Internet use by illiteracy, financial obstacles or lack of access to the necessary technology.

In the discussion below, we shall be concerned only with those at the other end of the scale: the educated young Moroccans who are best placed to take advantage of the World Wide Web. Moreover, even within this category, we shall consider only the small elite with advanced proficiency in English. Of all Moroccans, these are the Internet-users who have access to the largest amount of online material and who are in a position to communicate directly with the huge community of other Anglophone Internet-users. It must be stressed that this group is not representative of Moroccan students as a whole, most of whom do not have a high degree of proficiency in English, and generally choose to surf the Web using French or Arabic rather than English. Nor, of 
course, can students necessarily be considered representative of a broader population (as LaRose (2004) points out, there are differences between students and other groups which are likely to be reflected in their Internet use).

It is hypothesized that the Internet may represent a particularly important opportunity for these Moroccan students, for at least two reasons. First, its role as a source of information might be more important for these students than for their peers in the industrialized world because of the relative paucity of other information sources accessible to them: in Morocco, university libraries are not very rich in resources, subscriptions to scholarly journals are rare and foreign newspapers are expensive. Second, the Internet could represent an important means of contact with the wider world. While these students can gaze across the Straits of Gibraltar at the southern coast of Spain every day from their homes in Tangier, very few of them have ever had the chance to cross this narrow stretch of water, since European visas for Moroccans, particularly students, are becoming ever more difficult to obtain. Compared to their counterparts on the northern shores of the Mediterranean, who can cross borders freely and have vast libraries at their disposal, then, these Moroccan students may well see the Internet and the World Wide Web as an emancipating space where they can cross virtual borders and access free-for-all information.

And yet our own observation of our teenage son's Internet usage seems to cast doubt on the extent to which young Moroccans actually exploit the Internet for these purposes. $\mathrm{He}$ and his peers, mostly students of the American high schools in Morocco, are online every day, often for most of the weekday evening, and the vast majority of the time they spend online is devoted to instant messaging using MSN Messenger. Although our son does communicate via this medium with contacts he has never met, the dialogue is mainly between him and his classmates and friends within the same city; after spending time with them during the day in school, he continues to text them all evening. This seems to have replaced the telephone as a more economical method of maintaining adolescent networks - very much a local activity. Moreover, the group has developed a very specific language variety, involving not only the usual types of abbreviation, icons, etc., characteristic of instant messaging styles (see Crystal, 2006), but also constant switching between English, Arabic (written in Latin script) and French. This mixture constitutes a very strong in-group marker, and would probably be impenetrable for anyone outside the group. Such admittedly anecdotal evidence raises the possibility that the Internet, rather than opening up new horizons, may well serve to maintain existing local group identities.

Our aim here is merely to raise the question of whether, for young educated Moroccan multilinguals, the Internet lives up to its image as a gateway to knowledge and an intercultural meeting place. In what respects do they perceive the Internet to be useful, and to what extent does it provide gratification of their needs? In particular, do they feel that their needs for information and communication are gratified via this medium?

The information presented here is based on responses to two questionnaires. Both questionnaires were administered to a total of 96 university students aged between 21 and 28 , who were either preparing a degree in English or who al- ready held such a degree and were pursuing postgraduate studies. These were not a random sample, but were simply our own students, who were given the questionnaires in printed form and asked to complete them in writing.

The first questionnaire was drawn up after an informal discussion on uses of the Internet with a group of students similar in background to the informants. The remarks made in this discussion were used to establish a list of Internet activities, which were then included in the questionnaire with a request for the informants to indicate which they personally carried out. The questionnaire also elicited information about Internet habits, perceptions of the material available on the World Wide Web and open-ended questions eliciting attitudes to the Internet and its impact on the informants' lives. Informants were asked to provide concrete examples to support their answers.

Reservations about the value of such self-reports on usage are of course regularly expressed. Even in an anonymous questionnaire, respondents may provide answers aimed at projecting a particular image of themselves; thus in our case, they may well have wished to appear as studious persons, skilled at information gathering, rather than as time-wasters obsessed with trivia. Moreover, given the small numbers of informants, the investigation reported on below should be regarded merely as a pilot study which may identify issues worth exploring in a more extensive survey.

All the informants described themselves as being regular Internet users: $86 \%$ of them reported using the Internet daily or every other day, and $77 \%$ of them claimed to have been using it for five years or more. While $51 \%$ claimed to use it at home, $79 \%$ said they frequented the Internet cafés which are to be found on almost every street in Moroccan city centres. Out of 16 Internet activities presented to them in a list, those they claimed to practise most frequently were information gathering $(75 \%$ said this was a frequent activity), emailing $(67 \%)$, instant messaging $(60 \%)$, checking on the news $(47 \%)$, and consulting online dictionaries (44\%). On the other hand, they seemed to make relatively little use of other possibilities; only $9 \%$ claimed to make frequent phone calls over the Internet and only $7 \%$ said they frequently listened to online radio, while $28 \%$ said they listened to music and $15 \%$ that they downloaded music or clips. No informant claimed to play online games frequently.

These responses suggest that, of the categories of gratifications identified by McQuail, Blumler and Brown (1972), those of surveillance (information gathering) and personal relations are most important for the informants; these correspond to Stafford's (2004) content and social gratifications. The figures thus contrast with those obtained by Ferguson and Perse (2000), where entertainment was the dominant gratification. The choices reported by our informants may perhaps reflect the conditions in which they use the Internet. Much of their time online is spent in public places such as Internet cafés, where activities involving listening might be impractical; and the low speed Internet access generally available to them means that downloading video or audio files is often impracticable.

It is also worth noting that not one informant claimed ever to have bought anything over the Internet. This last finding obviously reflects the reality of Morocco today, 
where the use of credit cards is very limited, and foreign exchange still tightly controlled; those who make sweeping claims to the effect that 'the rise of the Internet allows commerce to take place from anywhere, to anywhere, and is open to anyone' (Kluver, 2000) are obviously unaware of the fact that such constraints still hold in much of the third world.

The responses of the informants suggested that they definitely considered the Internet to be making a positive contribution to their lives: $78 \%$ cited access to information as a benefit of the Internet, while $28 \%$ cited the ability to keep in touch with friends. Smaller numbers cited other benefits such as improving their computer skills (13\%), developing their personality $(6 \%)$, or simply enjoying themselves (only $4 \%$ ). As for negative effects, $43 \%$ mentioned wasting time and $16 \%$ worried about becoming addicted to the Internet. An optimistic $82 \%$ felt that the Internet had improved their knowledge of other cultures, while only $13 \%$ did not judge this to be the case; and $75 \%$ felt that use of the Internet promotes understanding between different cultures, as opposed to $16 \%$ who claimed that it encourages stereotyping and $9 \%$ who felt it makes no difference to perceptions of the Other. Clearly, then, the informants were generally enthusiastic about the Internet and its applications.

$63 \%$ of the informants claimed to have made new friends over the Internet, and $60 \%$ claimed to have contacts abroad whom they had never met in person. On the other hand, when asked to give details, only $31 \%$ actually managed to cite examples of such acquaintances. The detailed comments they made often revealed that the contacts they valued were with friends studying abroad, distant relations or young people of Moroccan origin living in Europe. Several also mentioned that they were in contact with Muslims from other countries, such as young British people of Pakistani origin. They also insisted on the usefulness of the Internet for keeping in touch with friends at home, it being more economical than phone calls or snail mail. As for the people they had met over the Internet, several remarked that such friendships remained superficial, or were generally short-lived; some said that they had previously been in the habit of seeking out such relationships but had now stopped. To quote one student's comment on Internet contacts abroad: 'Talking to them is like talking to anyone else; almost all people are starting to think the same way'. It would seem from these responses, then, that despite paying lip service to the idea of the Internet as a place for experiencing cultural diversity, this group tends to use the Internet mainly to communicate with people similar to themselves, rather than people from vastly different cultural backgrounds.

As for their use of the web as a fund of information, while $46 \%$ claimed that they usually found the information they wanted quickly and easily, $49 \%$ admitted that they found it only after wasting a lot of time, and 5\% that they often did not find what they needed at all: remarks which fit in with Ebersole's (2000) observation that students frequently fail to find the excellent information available on the Web.

The kinds of information they claimed regularly to seek out via the Internet were mainly news (cited by $42 \%$ ), the meaning of unfamiliar vocabulary (38\%), and materials they needed for coursework (34\%). Asked what kinds of material they would most like to have access to, $13 \%$ mentioned books (understandably, as apart from local products, books tend to be expensive and not easily obtainable in Morocco), $10 \%$ mentioned documentation relevant to their studies, and $7 \%$ mentioned types of information which could be classed as local (such as announcements of job vacancies, instructions for administrative procedures, and even in one case Moroccan recipes). Like the high school students mentioned above, then, their preoccupations seem to be largely with the needs of their everyday life rather than with the exploration of more distant horizons.

They do appear to be conscious of some limitations of the web as an information source. Thus $80 \%$ felt that the web contained a mixture of reliable and misleading information, whereas only $3 \%$ felt it was mainly reliable; $56 \%$ claimed to have personally encountered inaccurate information, $73 \%$ misleading information, and $77 \%$ offensive material. The examples they offered are quite enlightening; we find, for instance, complaints about inaccurate and misleading information about Islam, the Arab world, and in particular about Palestine, the Lebanese crisis and the Polisario. Other subjects less frequently cited included misleading medical information (for instance, claims of a cure for AIDS) and wrong advice about obtaining visas and green cards for admission to the USA. The examples of offensive material given often also centred on material critical of Islam or insulting to Arabs.

In fact, then, the examples they offered reflect their own spheres of interest and tend to be closely tied to their own world view, rather than revealing a concern about racism as a worldwide phenomenon, or attacks on other religions. There seems to be something of a paranoid feeling among them that the Internet is being used to attack Arabs and Muslims. This can be compared to the observations made by Alterman (1998) about Syrians' attitudes to the Internet; he reports a generalized view among Syrians that the Internet is full of anti-Syrian propaganda, citing one study of materials dealing with the Israeli/Palestinian conflict which identified them as $100 \%$ anti-Syrian in bias! The authorities in certain Arab states also seem to have adopted defensive positions, portraying the web as a purveyor of anti-Arab propaganda (see for instance Bahgat's (2004) study of the situation in Egypt). Moroccan students are thus not alone in complaining about materials which offend their own sensitivities, without acknowledging that offence may also go in other directions.

Given that a high proportion of the students claimed to use the web as a source of news, and $35 \%$ also said they consulted it as an alternative to reading newspapers, a further questionnaire was administered to the same group of informants. This aimed at getting an impression of their ability to discriminate between true and false news stories. Here the informants were given 12 brief 'news' items, which were a mixture of true stories, both local and international, and hoax stories of the type widely transmitted over the Internet. They were asked to indicate whether they believed each story to be true or false or were unable to judge its veracity.

The results were quite striking. Of the five true stories included in the test, only one (concerning the murder of two Europeans in Rabat) was correctly identified as true by a majority of the students $(76 \%)$. In the case of the other true news stories, which dealt with the burial of the mother of the last tsar of Russia, South Korea's efforts to get its candidate 
chosen as UN secretary general, Bush's position on abortion and a French charity's gift of bicycles to Moroccan country schoolgirls, no more than one third of our informants correctly identified any of them as true.

On the other hand, of the seven hoax stories, only one, the story of HIV infected needles being placed on cinema seats, which has been circulating on the Internet for a number of years, was identified as false by a majority of informants; and even in this case, only $54 \%$ rightly dismissed the story as a hoax. $56 \%$ of the students claimed to believe the story of the 4000 Jews not turning up for work at the World Trade Center on $9 / 11,50 \%$ claimed to believe that Neil Armstrong heard a voice saying Allahu akbar when he stepped onto the moon and immediately converted to Islam on his return to earth, and $23 \%$ even accepted as true the story that Tommy Hilfiger declared on the Oprah Winfrey show that he did not want his clothes to be worn by blacks or Asians. Remarkably, 14\% even claimed to believe a story that Bill Gates was trying to buy the Catholic Church, while a further $40 \%$ said they did not know if it was true or not. The poor performance of these after all highly educated Anglophone Moroccan students on discriminating hoaxes from true stories suggests that, despite their perception of the Internet as a valuable source of information, they are not particularly up-to-date with events either in Morocco or outside it, and they do not appear to be very discerning information consumers.

While the investigation reported on here represents only a pilot study of one small group of Moroccan internet users, we hope it will serve to draw attention to the situation of third world internet users, their particular needs and perspectives. We have also sought to illustrate the fact that stereotyped views of the Internet as a fountain of knowledge and a bridge between cultures should not be taken for granted. Much more investigation needs to be done to evaluate the extent to which the bold claims so often made for the Internet are valid for specific categories of user. Our preliminary enquiry has suggested that as well as being a source of information, the Web can also promote false beliefs, and that the Other who is encountered online may not necessarily offer a new world view, but rather reinforce existing preconceptions.

\section{REFERENCES}

Alterman, J.B. (1998). New media, new politics? From satellite television to the Internet in the Arab world. Washington: Washington Institute for Near East Policy.

Bahgat, H. (2004). Egypt's virtual protection of morality. Middle East Report, No. 230, 34(1) 22-25.

Beckett, R. (2004). Communication ethics and the Internet: Intercultural and localising influencers. International Journal of Information Ethics 11/2004, 2:1-8. Retrieved 24 March, 2008 from the World Wide Web: http://www.i-r-i-e.net/inhalt/002/ijie_002_04_beckett.pdf

Blumler, J., \& Katz, E. (1974). The uses of mass communications. Beverley Hills: Sage Publications.
Chen, G.M. (1998). Internet communication via e-mail debate. The Edge 1(4). Retrieved 23 March, 2008 from the World Wide Web: http://cms.interculturalu.com/theedge/v1i4Fall1998/f98chen.html

Crystal, D. (2006). Language and the Internet, (2nd ed.), Cambridge: Cambridge University Press.

Dahan, M. (2003). Between a rock and a hard place: the changing public sphere of Palestinian Israelis. Journal of Computer-mediated Communication 8(2). Retrieved 20 March, 2008 from the World Wide Web: http://jcmc.indiana.edu/vol8/issue2/dahan.html

Ebersole, S. (2000). Uses and gratifications of the Web among students. Journal of Computer-Mediated Communication 6(1). Retrieved 26 April, 2008 from the World Wide Web: http://jcmc.indiana.edu/vol6/issue1/ebersole.html

Faiola, A., \& Matei, S.A. (2005). Cultural cognitive style and web design: Beyond a behavioural inquiry into computer-assisted communication. Journal of Computer-Mediated Communication 11(1). Retrieved 20 March, 2008 from the World Wide Web: http://jcmc.indiana.edu/vol11/issue1/faiola.html

Ferguson, D., \& Perse, E. (2000). The World Wide Web as a functional alternative to television. Journal of Broadcasting \& Electronic Media 44(2): 155-174

Franklin, R.A. (2008). The hate directory: Hate groups on the Internet. Retrieved 24 March, 2008 from the World Wide Web: http://www.bcpl.net/ rfrankli/hatedir.htm

Friedman, T. (1999). The Lexus and the olive tree: Understanding globalization. New York: Farrar, Strauss and Giroux.

Hanna, B.E., \& de Nooy, J. (2004) Negotiating cross-cultural difference in electronic discussion. Multilingua, 23(3): 257-281.

Hargittai, E. (1998). Holes in the net: The Internet and international stratification. Paper presented at the INET98 Conference. Retrieved 24 October, 2006 from the World Wide Web: http://www.isoc.org/inet98/proceedings/5d/5d_1.htm

Hongladarom, S. (2007). Negotiating the global and the local: How Thai culture co-opts the Internet. First Monday Special Issue No. 8. Retrieved 24 March, 2008 from the World Wide Web: http://www.firstmonday.org/issues/issue5_8/hongladarom/index.ht $\mathrm{ml}$

Internet world stats (December 2007). Retrieved 25 March, 2008 from the World Wide Web: http://www.internetworldstats.com/stats1.htm

Katz, E., Gurevitch, J.G., \& Haas, M. (1973). On the use of the mass media for important things. American Sociological Review, 38(2): 164 181 .

Kluver, R. (2000). Globalization, informatization and intercultural communication. American Communication Journal 3(3). Retrieved 23 March, 2008 from the World Wide Web: http://www.acjournal.org/holdings/vol3/Iss3/spec1/kluver.htm

McQuail, D., Blumler, J.G., \& Brown, J.R. (1972). The television audience: A revised perspective. In D. McQuail (Ed.), Sociology of mass communications (pp. 135-165). Harmondsworth: Penguin.

LaRose, T. (2004). A social cognitive theory of Internet uses and gratifications: Toward a new model of media attendance. Journal of Broadcasting \& Electronic Media, September 2004. Retrieved 26 April, 2008 from the World Wide Web: http://findarticles.com/p/articles/mi_m6836/is_3_48/ai_n25096765

Severin, W.J., \& Tankard, J.W. (1997). Uses of mass media. In Severin, W.J. \& Tankard, J.W. (Eds.), Communication theories: Origins, methods, and uses in the mass media, 4th ed. (pp. 329-341). New York: Longman.

Stafford, T. F. (2004). Determining uses and gratifications for the Internet. Decision Sciences, Spring 2004. Retrieved 26 April 2008, from the World Wide Web: http://findarticles.com/p/articles/mi_qa3713/ is_200404/ai_n9398988

United Nations Press Release SG/SM/6502 SAG/4, March 24, 1998. Retrieved 26 March, 2008 from the World Wide Web: http://www.un.org/News/Press/docs/1998/19980324.SGSM6502.ht $\mathrm{ml}$ 